\title{
Long-term behavioural impact of an integrated home garden intervention: evidence from Bangladesh
}

\author{
Ghassan Baliki $^{1,2} \cdot$ Tilman Brück ${ }^{1,2} \cdot$ Pepijn Schreinemachers ${ }^{3} \cdot$ Md. Nasir Uddin ${ }^{4}$
}

Received: 11 March 2019 / Accepted: 13 August 2019 /Published online: 3 September 2019

(C) The Author(s) 2019

\begin{abstract}
Integrated home garden interventions combine training in gardening practices with education about nutrition knowledge. Such interventions have been shown to improve nutrition behaviour in low income countries. However, to date rigorous evidence is lacking for their long-term impact. We test the impact of an integrated home garden intervention on vegetable production and consumption three years after the intervention ended. We analyse three rounds of survey data for 224 control and 395 intervention households in rural Bangladesh. Three years after the intervention, the average impact on vegetable production per household was $43 \mathrm{~kg} / \mathrm{year}(+49 \%$ over baseline levels; $p<0.01)$, and the effect was not statistically different from the impact one year after the intervention, which demonstrates that impact was maintained in the long-term. The impact on the micronutrient supply for iron, zinc, folate and pro-vitamin A from home gardens was maintained in the longterm. These impacts may have been driven by the long-term improvements in women's nutrition knowledge and gardening practices, explaining the sustainability of the behavioural nutrition change. We also identify positive impacts on women's empowerment and women's output market participation, highlighting how integrated programs, even if modest in scope, can be drivers of social change.
\end{abstract}

Keywords South Asia $\cdot$ Agriculture $\cdot$ Nutrition outcomes $\cdot$ Food security $\cdot$ Behaviour change $\cdot$ Gender

\section{Introduction}

The health, productivity and well-being of two billion people worldwide is compromised every year because their

Ghassan Baliki

baliki@igzev.de

Tilman Brück

brueck@igzev.de

Pepijn Schreinemachers

pepijn.schreinemachers@worldveg.org

Md. Nasir Uddin

nasir@gbf-bangladesh.org

1 Leibniz Institute of Vegetable and Ornamental Crops, Theodor-Echtermeyer-Weg 1, 14979

Großbeeren, Germany

2 ISDC - International Security and Development Center, Auguststr. 89, 10117 Berlin, Germany

3 World Vegetable Center, P.O. Box 1010 (Kasetsart), Bangkok 10903, Thailand

4 Grameen Bikash Foundation, Bogra, Bangladesh bodies are deficit in essential micronutrients such as vitamin A, iron and zinc (Beal et al. 2017). Children under five years of age are particularly vulnerable (Rivera et al. 2003; Bhan et al. 2001). As women are nearly always in charge of food preparation, it is important to enable them to provide nutritious meals to their families. Yet, women's knowledge, control of resources, and decision-making about food production is often compromised, particularly in strongly patriarchal rural societies (Sraboni et al. 2014). One domain in which women have relatively more autonomy is the home garden (Rybak et al. 2018; Schaetzel et al. 2014; Patalagsa et al. 2015; Hillenbrand 2010). Previous studies have shown that even small home gardens can provide a substantial supply of essential micronutrients and contribute to dietary diversification (Weinberger 2013; Keatinge et al. 2011). This is important because interventions such as supplementation, food fortification and biofortification, although making a much-needed impact on abating micronutrient malnutrition, are not directly contributing to diversifying food systems and human diets, and a lack of diversity of these is an important underlying driver of malnutrition. Furthermore, nutrition interventions should induce long-lasting behavioural changes to be sustainable. 
Building women's knowledge and skills to manage their home gardens could therefore be an important pathway to improving household nutrition in the long-term. We test this hypothesis rigorously in our paper, drawing on evidence from a multi-year study of an intervention to support women's home gardens and nutrition in rural Bangladesh. In doing so, the study addresses a broader question in economic development by assessing if a development intervention, which is modest in scope and duration and which is focused on nutrition-sensitive agriculture, has the potential to induce long-term behaviour change among women who are strongly constrained by local cultural gender norms - and, indeed, if these norms themselves can be changed in such a way.

Home garden interventions usually integrate training in gardening techniques (e.g., use of quality seed, planting bed preparation, crop rotation, compost making and pest and disease management) with nutrition education aimed at transferring nutrition knowledge (e.g., which crops contain which essential nutrients) and nutrition skills (e.g., how to prepare food to maintain nutrients) (World Vegetable Center 2016). Outside support is usually provided for one year and only in exceptional cases for a period up to three years (Osei et al. 2017).

There is growing evidence that integrated home garden interventions are effective in increasing the consumption of nutritious food among poor rural households in developing countries (Olney et al. 2009, 2013; Schreinemachers et al. 2016; Tesfamariam et al. 2018; Osei et al. 2017). Several recent reviews have identified that such interventions are one of few agricultural interventions with a proven impact on increased vegetable consumption, although the evidence basis for nutritional status remains weak (DFID 2014; Ruel et al. 2013). Home garden interventions have been scaled up in several countries, including Ethiopia (Hirvonen and Headey 2018), Cambodia (Schreinemachers et al. 2018) and Bangladesh (Bushamuka et al. 2005; Iannotti et al. 2009; Schreinemachers et al. 2015).

There is, however, a significant knowledge gap about the impact of home gardens in the long-term, as there are, to our knowledge, no rigorous, theory-based impact evaluations using panel data studying the effect of home gardens on nutrition (and gender) outcomes three years or more after the intervention support has ended.

Key studies to date have quantified the impact of home garden programs while households were still receiving intervention support or immediately after support had ended. For instance, Olney et al. (2009) studied the impact of a 3-year home garden support program in Cambodia while there were 1.5 years in between the baseline and endline surveys. Furthermore, in the study of Olney et al. (2015) for Burkina Faso there were two years between baseline and endline surveys while program support was also provided for two years. Osei et al. (2017) studied the impact of home gardens in Nepal with three years in between baseline and endline while program support was given for an equally long period of time. Schreinemachers et al. (2016) quantified the impact of home gardens in Bangladesh one year after the program had ended.

An exception is the study of Bushamuka et al. (2005) for Bangladesh, which compared the impact between households that still received support to that of households that no longer received support and found that the mean impact on fruit and vegetable production was not statistically different for these two groups. Furthermore, Zimpita et al. (2015) studied home gardens in South Africa ten years after the intervention ended and found that about a third of the household continued to grow the same $\beta$ carotene-rich fruit and vegetables that had been introduced by the program and that this proportion was very similar one, six and ten years after the project ended. However, both of these studies do not provide estimates on the average treatment effect of the programme, and for the case of Zimpita et al. (2015) there is no control group to test the counter-factual. The absence of a rigorous impact design in current studies does not allow disentangling the true causal long-term impacts of homestead gardening on production and consumption behaviour, as well as gender outcomes.

Our study hence fills this important knowledge gap and provides novel rigorous evidence on the long-term impacts of home gardens. The provision of such evidence is critically important as home garden interventions are relatively costly compared to alternative nutrition interventions such as fortification and supplementation. Yet, if it can be shown that home garden interventions address the root causes of micronutrient deficiencies by inducing behaviour changes sustained over many years, then such evidence would have strong implications for policy and programming.

We conducted our study in Bangladesh for several reasons. In the past decades, Bangladesh has witnessed considerable improvements in health and nutrition (Chowdhury et al. 2013). The reduction in malnutrition, especially among children below five, has been large and has been explained by incremental changes in wealth accumulation and education (Headey et al. 2015). However this trend has not correlated with changes in healthy eating habits (Jain 2018). Home gardens are typical in Bangladesh and can play an effective role in increasing the consumption of healthy food (Schreinemachers et al. 2015). Our study contributes to on-going academic and policy debates on nutrition, agriculture and gender in rural Bangladesh. Moreover, our study sites in rural Bangladesh are not atypical for many rural economies elsewhere in South and SouthEast Asia, providing a high degree of external validity to our study. 
We contribute to the literature on food consumption and nutrition as well as on the literature on behaviour change induced by agricultural interventions in several ways. First, our study is one of the first to address the long-term sustainability of home garden interventions in a rigorous manner, using a quasi-experimental approach and tracking the same households over three years after the intervention ended. Second, we provide novel evidence regarding the mechanisms through which the nutritional impact is achieved, differentiating and measuring nutrition knowledge and garden practices. Third, the study provides original causal evidence on some social impacts beyond the nutrition and agricultural spheres, underscoring the importance of integrated home garden interventions on women's empowerment and decision-making within the household.

The remainder of the paper is structured as follows. We first describe the home garden intervention studied in this paper, the methods applied, and the data collected. The subsequent section presents the intervention's impact on vegetable production and consumption. We also investigate the mechanisms and secondary outcomes. The contribution of these findings are presented in the discussion section. The final section concludes.

\section{Data and methods}

\section{The home garden intervention}

The integrated intervention's theory of change has three components, intended to re-enforce each other. First, the nutrition training should increase women's knowledge of nutrition to stimulate their interest to regularly include vegetables in meals (a change on the demand side). Second, women's ability to successfully produce vegetables in their home garden should be enhanced through the garden training, strengthening their practices (a change on the supply side). Third, women receive quality seeds (i.e. seed of suitable varieties produced by certified seed producers), which is a change at the market level. Most of the garden production is expected to be consumed within the own household rather than marketed, although small amounts may be shared with neighbours or sold. The intervention's primary focus is on agricultural and nutritional outcomes. Targeting women within the household is important as women in Bangladesh (and elsewhere) have a key role to play in providing household nutrition (Malapit et al. 2019). Furthermore, there is evidence showing that home garden interventions can help women gain recognition from their husbands and peers for their increased knowledge and skills, contributing to women's empowerment (Schaetzel et al. 2014; Patalagsa et al. 2015; Hillenbrand 2010). However, we note that the intervention's theory of change did not rely on female empowerment to take place for the intervention to succeed. In that sense, impacts of the intervention on female empowerment are secondary (or indirect).

The home garden intervention analysed here targeted women in poor rural communities in Jessore, Barisal, Faridpur and Patuakhali Districts of Bangladesh. Households had to meet three main criteria to be eligible for the intervention: (i) the household had to have some land but not more than one acre $(0.4 \mathrm{ha})$ to ensure that it targeted poor smallholder households (while noting that landless households may even be poorer, but were not targeted by this intervention); (ii) the woman (spouse of the household head) had to have some experience in growing vegetables, but not have received similar support in the past; and (iii) the woman needed to have an interest to participate in the project. Additionally, households with a child below the age of five were prioritized though also other households were included if they met the other criteria.

The selected women, mostly mothers and only one per household, were invited for a one-day intensive training that focused on nutrition and garden techniques. It took place in groups of 10-15 women at a local training centre. The training included classroom teaching and hands-on practice in a demonstration garden. In the classroom, women also learned about the importance of nutrition in preventing diseases, the physiological functions of various nutrients for human health, the nutritional value of commonly consumed vegetables, and nutrients in vegetables of different colour. Women also learned how to cook vegetables to preserve nutritional value. The garden training addressed site selection, site and land preparation, garden layout and design, raised planting bed preparation, proper fencing, seasonal vegetable selection, sowing practices, fertilizer application, irrigation and drainage, weeding, and insect and disease management without pesticides. Home gardens are common in Bangladesh, but this intervention demonstrated a different home garden design using raised planting beds, crop rotation, construction of fences with synthetic nets and locally available materials to keep out farm animals, and the importance of using quality seed. After the training, participants were encouraged to share the acquired knowledge with their neighbours. The intervention was not specifically tailored to encourage women to make decisions independently or induce change in the intra-household decision-making process.

Participants received a follow-up visit 7 to 14 days after the training by the training officers who helped to set up the garden and answered questions. Once a training officer observed that a garden was prepared well, the respective woman received seed packs of improved open pollinated vegetable varieties selected by the project team for ease of growing, cultural acceptance, and high nutrient content. 
This selection included stem amaranth/red amaranth, bitter gourd, Indian spinach, okra, water spinach, and yardlong bean. Cucumber was also included because of local preferences, although it does not have a high micronutrient content. The women also received vines of sweet potato for harvesting leaves and young shoots. The training officers visited the households on an almost weekly basis for the first six months following the training and reviewed nutritional messages as well as garden practices. For the subsequent six months, the visiting frequency was monthly. The average cost of the intervention was about USD 55.3 per home garden, including all direct and indirect project costs (Schreinemachers et al. 2016). The project was funded by the United States Agency for International Development (USAID) and implemented by the World Vegetable Center in partnership with the non-governmental organizations BRAC and Proshika. Between 2012 and 2015, over 10,000 women received the training, but this study focuses on a random sample of women selected in 2013.

\section{Research design}

We employ a quasi-experimental approach in the design of the study, comparing households in an intervention group that received the program and a comparable control group of households from different villages that were not included in the program. Tracking the same households over a period of three years, we use three rounds of survey data in our analysis, which were collected before the intervention
(2013), one year after the intervention (2014), and three years after the intervention (2016).

The sample of intervention households was selected using a stratified random sampling method that purposely selected 12 upazillas (subdistricts) and 17 unions (clusters of villages) and then randomly selected 28 villages from these unions. All intervention households from these villages were included in the sample.

The sample of control households was selected from 8 upazillas and 9 unions that were purposively selected to have similar characteristics (in terms of agro-ecology, village size, agricultural land use and market access) as the intervention unions. From these, 18 control villages were selected. All control households were selected from different villages from the intervention to prevent possible spillover effects. To minimize the effect of selection bias, the control group was selected using the same household eligibility criteria applied by the project to identify intervention households.

The baseline data exhibit no evidence of selection bias, as demonstrated by a comparison of household characteristics between the intervention and control groups (Table 1). Most importantly, there was no significant difference in the size of the home garden, the number of garden practices applied, the share of garden work, and the quantity of vegetables harvested during the summer and winter seasons. There was only a small difference in that control households observed a larger number of challenges in managing the home garden $(p<0.10)$. However, the difference is very

Table 1 Mean difference between intervention and control households at baseline, 2013

\begin{tabular}{llll}
\hline & Intervention & Control & $p$ \\
\hline Household size (persons) & $4.86(1.51)$ & $4.97(1.55)$ & 0.389 \\
Male & $2.37(1.07)$ & $2.49(1.19)$ & 0.224 \\
Female & $2.49(1.16)$ & $2.48(1.14)$ & $3.00(1.21)$ \\
Adults & $2.85(1.15)$ & $1.30(1.06)$ & 0.946 \\
Children (5 years \& above) & $1.39(1.01)$ & $0.67(0.61)$ & 0.133 \\
Children (below 5 years) & $0.62(0.60)$ & $0.76(0.43)$ & 0.308 \\
Cultivated garden (No = 0, Yes $=1)$ & $0.70(0.46)$ & $18.32(21.84)$ & 0.331 \\
Size of home garden $\left(m^{2}\right)$ & $21.24(29.12)$ & $0.02(0.20)$ & 0.117 \\
Practices used in garden (number of) & $0.02(0.12)$ & $0.75(1.17)$ & $69.65(20.89)$ \\
Challenges in garden (number of) & $0.56(1.07)$ & $27.62(19.88)$ & 0.159 \\
Share of garden work - women $(\%)$ & $69.83(20.08)$ & $2.72(6.54)$ & 0.628 \\
Share of garden work - men $(\%)$ & $26.66(19.66)$ & $86.90(128.86)$ & 0.057 \\
Share of garden work - children $(\%)$ & $3.51(7.55)$ & $38.06(83.10)$ & 0.930 \\
Total production $(\mathrm{kg})$ & $86.72(124.49)$ & $48.84(81.22)$ & 0.619 \\
Summer production $(\mathrm{kg})$ & $37.45(74.23)$ & $12.82(35.72)$ & 0.263 \\
Winter production $(\mathrm{kg})$ & $49.27(85.06)$ & $17.49(42.11)$ & 0.978 \\
Leafy vegetables production $(\mathrm{kg})$ & & 0.913 \\
\hline
\end{tabular}

Notes: Standard deviation in parentheses. Welch two sample t-test with unequal variance 
minimal and it explains less than $2 \%$ of the variance in vegetable production at baseline. We therefore conclude that the sample was balanced at baseline.

To quantify program impact, we employ a difference-indifference estimator, defined as:

$$
\begin{aligned}
\text { Outcome indicator }= & \alpha+\beta \cdot(\text { Intervention }) \\
& +\gamma \cdot(\text { Period }) \\
& +\delta \cdot(\text { Intervention } \times \text { Period })(1)
\end{aligned}
$$

in which, Intervention is a dummy variable $(1=$ Intervention group; $0=$ Control group) and Period is a dummy variable $(0=$ Baseline $; 1=$ Follow-up $)$. The model therefore controls for structural differences between intervention and control and for common changes between baseline and follow-up. The parameter of interest is $\delta$, which is the average treatment effect (ATE) and quantifies the difference in mean outcomes between households in the intervention and control groups. Our key assumption is that the average change in the control group represents the counter-factual change in the intervention group in the absence of the project (Gertler et al. 2016). This "parallel paths" assumption is likely to hold for our study because the number of control and intervention villages is large (46 villages) and were selected from the same sub-districts.

To substantiate our findings with regard to the mechanisms of the long-term impacts, we analysed the determinants of the variation in total quantity of vegetables produced as well as for leafy and non-leafy vegetable production separately. This was done by regressing these production variables on a set of covariates including the number of gardening practices applied and the knowledge score, as well as control variables that may influence the decision to produce either type of crop including baseline quantities. The analysis was implemented for the full sample while controlling for intervention households, as well as for a sub-sample of only the intervention households.

\section{Variables}

In line with our discussion of the theory of change and the expected impact of the intervention, we focus on the following key variables:

Vegetable production is expressed in kilograms of fresh weight per household member per year. The variable was collected using a 12-month recall period, asking separately for the last summer (kharif) and the last winter (rabi). Harvested quantities were summed into five broad groups: cucurbits and eggplants; roots and tubers; fresh beans and pulses; leafy vegetables; and other vegetables (e.g. okra, tomato). The survey also recorded how the harvest was used.

We calculated nutrient yields from the vegetable production data using food composition tables (USDA 2015;
World Vegetable Center 2014). Selected nutrients included plant proteins, calcium, iron, folate, zinc, vitamin A (converted from pro-vitamin $\mathrm{A}$ and $\beta$-carotene contents) and vitamin C. Quantity of vegetables consumed was calculated using a 24-hour recall method and recorded the quantities of 32 different kinds of vegetables consumed by the whole household. Respondents were asked for the amount of raw vegetables used and the amount of leftover, which were deducted from the estimated quantity. It was expressed in grams per capita per day. 24-hours recall consumption data is only available for the two endline surveys.

We also defined several variables to delineate mechanisms through which the intervention may impact the primary outcomes: First, we quantified the percentage of households that had adopted various good gardening practices that were taught during the training, as discussed above, to measure the supply side mechanisms of home garden production. Second, we quantified women's knowledge of food and nutrition. For this we adapted 12 statements to the local cultural context and then asked all respondents to answer if each statement was correct or incorrect in their opinion. Half of the statements were factually correct and half were incorrect. For example, we asked about the statement "Cooking vegetables for a long time makes them more nutritious" (which is, of course, factually incorrect). The knowledge score was calculated by summing up the number of correct answers and normalising the index to take value between 0 and 1 . Third, we measured nutrition-sensitive behavioural changes adopted by women, particularly in regards to the cooking time of vegetables.

Other secondary outcome variables included a measure of women's self-perceived empowerment. Previous studies have shown that home garden interventions can make a positive contribution to gender equality (Patalagsa et al. 2015). We presented respondents with eight statement related to perceived social norms in the local cultural context. ${ }^{1}$ Respondents could reply on a 5-point scale from strongly agree to strongly disagree. For half of the statements, a lower score meant more empowerment and these were reverse coded before calculating the total empowerment score ranging from 0 to 32 . We then normalised the index to take a value between 0 and 1 . Our measure of women's empowerment is relatively simple compared to more advanced tools such as the women's

\footnotetext{
${ }^{1}$ The statements were: 1 . The woman should make decisions on her own regarding children's health. 2 . The man should make decisions by himself on how to spend the household money. 3. The woman should tell the man what food to buy and the man should do this. 4 . The woman does not have to consult the man on what to cook for dinner. 5. The woman should always ask the man for permission to go outside the compound. 6. The man has the right to scold/beat his wife if she does something wrong. 7. The man should have the final word when making joint decisions. 8 . The woman should always do what the man deems is best.
} 
empowerment in agriculture index (Alkire et al. 2013; Malapit et al. 2019).

A second variable included women's decision-making over the home garden. ${ }^{2}$ Respondents answered for 9 decisions regarding home garden management, whether they made the decision mostly by themselves or mostly by their husbands. The 5-point scale responses were then summed up into a single variable that ranged from 0 to 36 , where 36 indicates that all decision where always made by the woman. We also normalised this indicator to take a value between 0 and 1 . Both of these indicators were only collected at the long-term endline.

\section{Data collection}

Grameen Bikash Foundation, a Bangladeshi NGO, collected the household survey data. ${ }^{3}$ All data were collected in April-May during the end of the winter (rabi) season in the respective years, when home gardens are usually less productive because there is not much rain. Only women were interviewed and all selected women agreed to participate in the study. As shown in Table 2, sample attrition was $5 \%$ between baseline and first follow-up and $6 \%$ between baseline and second follow-up. The total balanced sample across all three waves includes 395 women in the intervention group and 224 women in the control group, bringing the total attrition rate to around $8.6 \%$. Balance tests between the attritor and the non-attritor groups at baseline show no statistically significance differences for our main outcome and explanatory variables. This is also true when comparing the intervention and control groups separately.

\section{Results}

\section{Long-term impacts on production and consumption}

Mean vegetable production from the home garden was 87 $\mathrm{kg}$ per household before the intervention. The difference-indifference estimates in Table 3 show that this mean quantity increased by $29 \mathrm{~kg}$ in the first endline (that is, one year after the intervention) and by $43 \mathrm{~kg}$ in the long-term endline (that is, three years after the intervention) vis-à-vis the baseline,

\footnotetext{
${ }^{2}$ The question was "Who takes the decision about the following activities in the home garden?": 1 . How much land to use for the home garden. 2. What crops to plant in the home garden. 3 . When to plant and harvest the home garden. 4. What inputs used in the home garden. 5 . When to water the plants in the home garden. 6 . Who does the work on the home garden. 7. How much produce to use from the home garden for own consumption. 8. How much produce to use from the home garden to sell. 9. Who keeps the money from selling vegetables.

${ }^{3}$ The authors jointly designed and supervised the 2016 long-term endline data collection. The data are available upon request.
}

with these changes being highly significant ( $p<0.01$ ). We observe an increase in impact of $14 \mathrm{~kg}$ between the first and the second endline as shown by the z-score, but it is not significant $(p=0.42)$. In summary, the initial increase in vegetable production after the intervention was sustained for three years.

However, during that period there is a significant change in the composition of vegetables produced. The intervention particularly promoted the production and consumption of leafy vegetables such as amaranth and water spinach and the production of these increased substantially immediately after the intervention while the production of eggplants and cucurbits decreased. This was reversed in the longterm endline when the volume of leafy vegetables was still higher than in 2013, but lower than in 2014. The production of cucurbits, on the other hand, was significantly higher. Hence, although the total quantity of vegetables harvested from the improved home garden was sustained from 2013 till 2016, the harvest in the long-term endline contained relatively more gourds than leafy vegetables. We will return to this in the discussion.

Given this compositional change, we tested if the impact on nutrient yields decreased over time (Table 4). It shows that the mean impact on values for iron, zinc, folate and vitamin A were lower three-years after the intervention than one-year after the intervention, which suggests a decreasing mean impact on nutrient yields. However, none of these changes were significant $(p>0.10)$ and therefore we cannot conclude that the supply of these nutrients declined. For calcium and vitamin $\mathrm{C}$ the impact was positive and significant at both endlines, but the three-year impact was significantly lower than the one-year impact.

Table 3 also disaggregates the impact of the intervention on vegetable production by usage. It shows that most of the increased production and indeed most of the home garden harvest was auto-consumed by the household. The auto-consumption of the harvest is important to ensure the nutritional impact of the home garden intervention. Furthermore, the table shows that more vegetables were sold in the long-term endline $(p<0.10)$ without compromising the effect on the quantity consumed. The share of women selling any vegetable in the market rose as a consequence of the intervention in the long-term by $20 \%(p<0.01)$ due to the intervention, which is also significantly different from the endline at 2014.

Figure 1 also confirms the positive impact of the intervention on vegetable consumption. It compares the distribution of vegetable consumption including potatoes for the sample of control and intervention households in the long-term endline. The data suggests that the intervention increased the mean level of vegetable consumption by $16.3 \%$ ( $p<$ $0.01)$. Furthermore, the kernel distribution shows that most of the differences are mainly driven by increments in 
Table 2 Sample size used in the study, in number of households

\begin{tabular}{llll}
\hline Survey & Intervention & Control & Total \\
\hline 2013 (baseline) & 425 & 252 & 677 \\
2014 (endline, 1 year after intervention) & 408 & 238 & 646 \\
2016 (long-term endline, 3 years after intervention) & 404 & 234 & 638 \\
Panel sample with complete data from 3 surveys & 395 & 224 \\
\hline
\end{tabular}

the lower levels of vegetable consumption (left-tail of the distribution), where the concentration of respondents in the intervention group below a consumption level of $150 \mathrm{~g}$ per day per capita is very low. Examining the difference for all three main meals of the day separately, we find that the increase in the daily per capita vegetable consumption

Table 3 Short- and long-term impact on home garden vegetable production

\begin{tabular}{|c|c|c|c|c|c|c|c|}
\hline & \multirow{2}{*}{$\begin{array}{l}\text { Baseline } \\
\text { Mean (SD) }\end{array}$} & \multicolumn{2}{|c|}{ Impact 2014} & \multicolumn{2}{|c|}{ Impact 2016} & \multicolumn{2}{|c|}{ Difference } \\
\hline & & ATE (SE) & $p$ & ATE (SE) & $p$ & z-score & $p$ \\
\hline Total quantity (kg) & $\begin{array}{l}86.71 \\
(126.02)\end{array}$ & $\begin{array}{l}29.44 \\
(11.29)\end{array}$ & 0.009 & $\begin{array}{l}43.19 \\
(12.59)\end{array}$ & 0.001 & 0.81 & 0.417 \\
\hline \multicolumn{8}{|l|}{ By crop category } \\
\hline Cucurbits (kg) & $\begin{array}{l}47.60 \\
(89.64)\end{array}$ & $\begin{array}{l}-12.83 \\
(7.90)\end{array}$ & 0.105 & $\begin{array}{l}23.62 \\
(8.80)\end{array}$ & 0.007 & 3.08 & 0.002 \\
\hline Roots \& tubers (kg) & $\begin{array}{l}1.87 \\
(14.52)\end{array}$ & $\begin{array}{l}3.04 \\
(1.62)\end{array}$ & 0.062 & $\begin{array}{l}0.87 \\
(2.08)\end{array}$ & 0.675 & -0.82 & 0.410 \\
\hline Beans \& pulses (kg) & $\begin{array}{l}15.13 \\
(38.38)\end{array}$ & $\begin{array}{l}6.29 \\
(3.31)\end{array}$ & 0.058 & $\begin{array}{l}5.46 \\
(3.52)\end{array}$ & 0.121 & -0.17 & 0.864 \\
\hline Leafy vegetables (kg) & $\begin{array}{l}15.80 \\
(39.95)\end{array}$ & $\begin{array}{l}23.17 \\
(3.40)\end{array}$ & $<0.001$ & $\begin{array}{l}6.29 \\
(3.66)\end{array}$ & 0.086 & -3.38 & $<0.001$ \\
\hline Other vegetables (kg) & $\begin{array}{l}6.31 \\
(29.64)\end{array}$ & $\begin{array}{l}9.77 \\
(3.06)\end{array}$ & 0.001 & $\begin{array}{l}6.94 \\
(3.94)\end{array}$ & 0.078 & -0.57 & 0.571 \\
\hline \multicolumn{8}{|l|}{ By usage } \\
\hline Consumed (kg) & $\begin{array}{l}50.13 \\
(66.34)\end{array}$ & $\begin{array}{l}26.58 \\
(6.28)\end{array}$ & $<0.001$ & $\begin{array}{l}30.33 \\
(7.41)\end{array}$ & $<0.001$ & 0.39 & 0.699 \\
\hline Shared $(\mathrm{kg})$ & $\begin{array}{l}11.51 \\
(19.25)\end{array}$ & $\begin{array}{l}4.49 \\
(1.66)\end{array}$ & 0.007 & $\begin{array}{l}1.78 \\
(1.84)\end{array}$ & 0.334 & -1.09 & 0.274 \\
\hline Sold (kg) & $\begin{array}{l}25.07 \\
(69.26)\end{array}$ & $\begin{array}{l}-1.63 \\
(5.90)\end{array}$ & 0.782 & $\begin{array}{l}11.36 \\
(6.19)\end{array}$ & 0.067 & 1.52 & 0.129 \\
\hline Sold $($ yes $=1 /$ no=0) & $\begin{array}{l}0.28 \\
(0.45)\end{array}$ & $\begin{array}{l}-0.10 \\
(0.06)\end{array}$ & 0.071 & $\begin{array}{l}0.20 \\
(0.05)\end{array}$ & $<0.001$ & 3.84 & $<0.001$ \\
\hline \multicolumn{8}{|l|}{ By season } \\
\hline Summer (kg) & $\begin{array}{l}37.60 \\
(77.50)\end{array}$ & $\begin{array}{l}29.15 \\
(7.09)\end{array}$ & $<0.001$ & $\begin{array}{l}22.14 \\
(7.54)\end{array}$ & 0.003 & -0.68 & 0.499 \\
\hline Winter $(\mathrm{kg})$ & $\begin{array}{l}49.11 \\
(83.63)\end{array}$ & $\begin{array}{l}0.29 \\
(7.33)\end{array}$ & 0.968 & $\begin{array}{l}21.05 \\
(8.39)\end{array}$ & 0.012 & 1.86 & 0.062 \\
\hline
\end{tabular}

Notes: ATE = Average Treatment Effect; SD = Standard Deviation; SE = Standard Errors. Baseline mean includes both intervention and control households. Impact mean in 2014 and 2016 are based on the difference-in-difference estimations. The difference in impact between 2014 and 2016 is based on the z-scores values. A negative z-score implies a negative change in impact and vice-versa. The total sample for each wave is equal to 619 of which 395 are in the intervention group and 224 in the control 
Table 4 Impact and change of impact on micronutrient per capita per day

\begin{tabular}{|c|c|c|c|c|c|c|c|}
\hline & \multirow{2}{*}{$\begin{array}{l}\text { Baseline } \\
\text { Mean (SD) }\end{array}$} & \multicolumn{2}{|c|}{ Impact 2014} & \multicolumn{2}{|c|}{ Impact 2016} & \multicolumn{2}{|c|}{ Difference } \\
\hline & & ATE (SE) & $p$ & ATE (SE) & $p$ & z-score & $p$ \\
\hline Total quantity (g) & $\begin{array}{l}51.98 \\
(81.75)\end{array}$ & $\begin{array}{l}15.05 \\
(7.31)\end{array}$ & 0.040 & $\begin{array}{l}21.90 \\
(8.35)\end{array}$ & 0.009 & 0.62 & 0.537 \\
\hline Plant proteins (g) & $\begin{array}{l}0.49 \\
(0.75)\end{array}$ & $\begin{array}{l}0.72 \\
(0.13)\end{array}$ & $<0.001$ & $\begin{array}{l}0.41 \\
(0.14)\end{array}$ & 0.004 & -1.62 & 0.105 \\
\hline Calcium (mg) & $\begin{array}{l}15.43 \\
(22.96)\end{array}$ & $\begin{array}{l}30.37 \\
(4.41)\end{array}$ & $<0.001$ & $\begin{array}{l}13.15 \\
(4.80)\end{array}$ & 0.006 & -2.64 & 0.008 \\
\hline Iron (mg) & $\begin{array}{l}0.23 \\
(0.37)\end{array}$ & $\begin{array}{l}0.32 \\
(0.06)\end{array}$ & $<0.001$ & $\begin{array}{l}0.20 \\
(0.07)\end{array}$ & 0.004 & -1.30 & 0.193 \\
\hline Folate (mcg) & $\begin{array}{l}11.28 \\
(18.03)\end{array}$ & $\begin{array}{l}15.65 \\
(2.98)\end{array}$ & $<0.001$ & $\begin{array}{l}8.76 \\
(3.28)\end{array}$ & 0.008 & -1.55 & 0.120 \\
\hline Zinc (mg) & $\begin{array}{l}0.18 \\
(0.28)\end{array}$ & $\begin{array}{l}0.23 \\
(0.05)\end{array}$ & $<0.001$ & $\begin{array}{l}0.15 \\
(0.06)\end{array}$ & 0.008 & -1.02 & 0.306 \\
\hline Vitamin A (1000 UI) & $\begin{array}{l}0.46 \\
(0.85)\end{array}$ & $\begin{array}{l}0.97 \\
(0.16)\end{array}$ & $<0.001$ & $\begin{array}{l}0.63 \\
(0.19)\end{array}$ & 0.001 & -1.37 & 0.171 \\
\hline Vitamin C (mg) & $\begin{array}{l}4.84 \\
(7.42)\end{array}$ & $\begin{array}{l}12.69 \\
(1.65)\end{array}$ & $<0.001$ & $\begin{array}{l}7.24 \\
(2.01)\end{array}$ & $<0.001$ & -2.10 & 0.036 \\
\hline
\end{tabular}

Notes: ATE $=$ Average Treatment Effect; $\mathrm{SD}=$ Standard Deviation; SE $=$ Standard Errors. Baseline means include both intervention and control households. Impact mean in 2014 and 2016 are based on the difference-in-difference estimations. The difference in impact between 2014 and 2016 is based on the z-score values. A negative z-score implies a negative change in impact and vice-versa. The total sample for each wave is equal to 619 of which 395 are in the treatment group and 224 in the control

is significant for all meals, and particularly for lunch and dinner.

We further break down the analysis by vegetable categories, and we find that the main differences in the daily per capita consumption are driven by leafy vegetables $(68.2$ grams in the treatment group and 42.3 grams in the control group with $p<0.01$ ) and roots and tubers (79.6 grams in treatment and 67.9 grams in control group with $p<0.01$ ). Most of the vegetable varieties that have been promoted by the intervention are still consumed at the long-term endline. For example $26 \%$ of households in the treatment group consumed Indian spinach in the last 24 hours versus $20 \%$ of households in the control group. Other promoted vegetables that are consumed at the household include yardlong beans, amaranth, okra, and bitter gourd. However, we do not find strong notable differences in the consumption of these vegetables across the two groups at the long-term endline.

\section{Secondary impacts}

Building on the intervention's theory of change, we now investigate why we observe these long-term impacts, focusing on behavioural changes in gardening and nutritionsensitive practices, knowledge, and women's empowerment and decision-making.
Three years after the intervention ended, there are clear differences in the use of home garden practices between intervention and control households (Table 5). For instance,

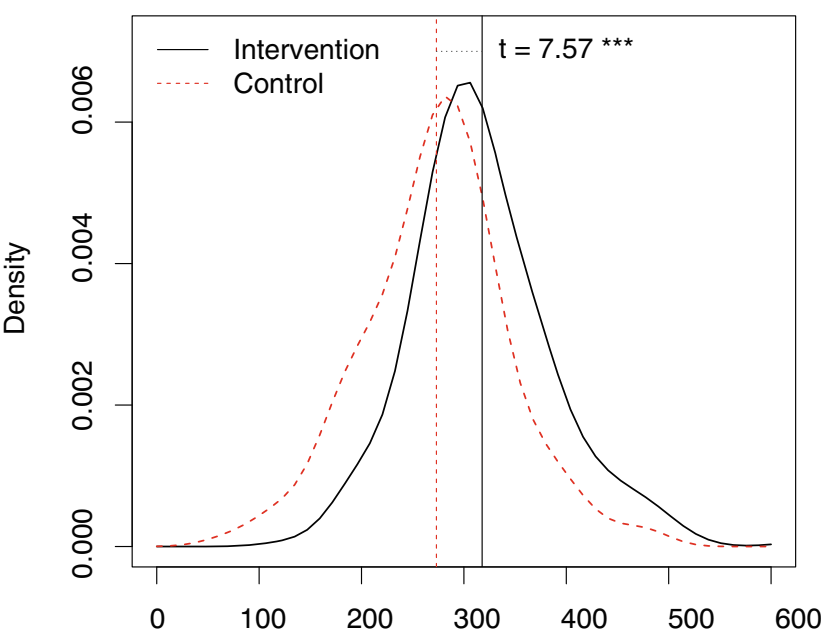

Daily per capita consumption of vegetables (grams)

Fig. 1 Kernel density distribution showing the difference in per capita vegetables consumed in the last 24 hours between control and intervention groups three years after the intervention. Note: The solid and dotted vertical lines show the means for the intervention and control group, respectively. The t- and p-values are derived from the Welch two sample t-test 
Table 5 Implementation of garden practices at long-term endline between intervention and control

\begin{tabular}{llll}
\hline & \multicolumn{2}{l}{ Long-term endline (2016) } \\
\cline { 2 - 4 } & $\begin{array}{l}\text { Control } \\
(\mathrm{n}=224)\end{array}$ & $\begin{array}{l}\text { Intervention } \\
(\mathrm{n}=395)\end{array}$ & $p$ \\
& 0.23 & 0.86 & $<0.001$ \\
\hline Raised beds & 0.12 & 0.38 & $<0.001$ \\
Inorganic fertilizer & 0.05 & 0.45 & $<0.001$ \\
Composting & 0.12 & 0.44 & $<0.001$ \\
Chemical pesticides & 0.09 & 0.31 & $<0.001$ \\
Bio pesticides & 0.00 & 0.07 & $<0.001$ \\
Mulches & 0.00 & 0.04 & $<0.001$ \\
Bagging (fruits) & 0.14 & 0.77 & $<0.001$ \\
Pruning & 0.77 & 0.94 & $<0.001$ \\
Stalking (trellis) & 0.55 & 0.93 & $<0.001$ \\
Strong fences & 0.50 & 0.90 & $<0.001$ \\
Irrigation & 2.56 & 6.09 & $<0.001$ \\
Practices (sum) & & & \\
\hline
\end{tabular}

Notes: Welch two sample t-test with unequal variance

$86 \%$ of the trained households planted vegetables on raised planting beds while this was practiced by only $23 \%$ of the control households $(p<0.01)$. The use of organic fertilizers, compost making, pruning, stalking, regular irrigation and the use of strong fences to keep out animals were all substantially higher among trained households $(p<0.01)$. However, the use of chemical pesticides was also higher, $44 \%$ as compared to $12 \%$ in the control $(p<0.01)$, which is worrisome as these should not be used in a home garden. We are not able using our survey to determine the reasons for the increase use in chemical pesticides. Spraying pesticides near the house can affect the health of family members and farm animals. Furthermore, insects can normally be removed by hand in a small garden and some blemishes can be tolerated if the produce is consumed within the own household.

The results also suggest substantial, positive and significant improvements in both nutrition-related knowledge and practices. Using kernel density graphs, Fig. 2 illustrates visually the mean differences between the intervention and control groups at long-term endline. A straightforward mean comparison between intervention and control groups at long-term endline retains the causal implications of the intervention given that household characteristics and key outcome variables were balanced at baseline. Panel (a) shows that the trained women scored on average $75 \%$ of the questions correctly compared to $40 \%$ of women in the control group. This strongly significant $73 \%$ improvement in the knowledge test about food and nutrition $(p<0.01)$ clearly shows that women in the intervention group were able to recall things that they were taught in the training. One of the training topics was about how to cook vegetables to best preserve nutrients, which generally meant reduced cooking times. The effect of this is shown in panel (b), which suggests that the mean cooking time was reduced by about 7 minutes from 31 to 24 minutes $(-23 \%$; $p<0.01$ ), which could have a positive effect on nutrient retention. These positive differences three year after the intervention show that the changes in nutrition-related practices and knowledge are crucial for the success of the intervention.

We proceed to examine the impacts of the intervention on women's empowerment in Fig. 3. Panel (a) demonstrates that women in the intervention group had greater control over decision-making related to the home garden and
Fig. 2 Kernel density distribution showing the difference in women's knowledge of food and nutrition (Panel a) and average cooking time of vegetables (Panel b) between control and intervention groups three years after the intervention. Note: The solid and dotted vertical lines show the means for the intervention and control group, respectively. The $\mathrm{t}$ - and $\mathrm{p}$-values are derived from the Welch two sample t-test

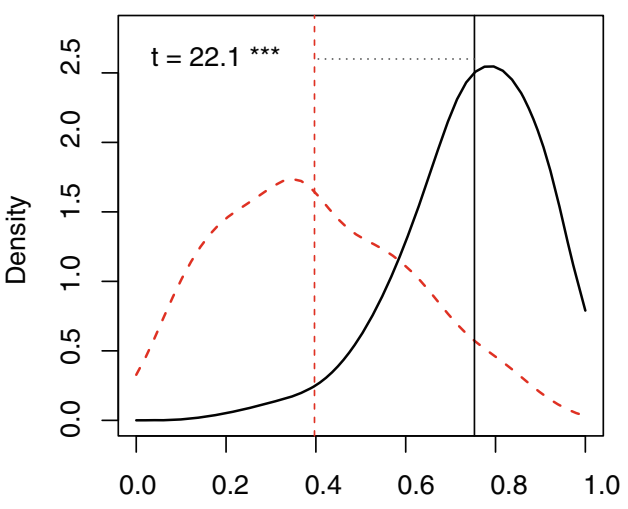

a) Knowledge of food and nutrition

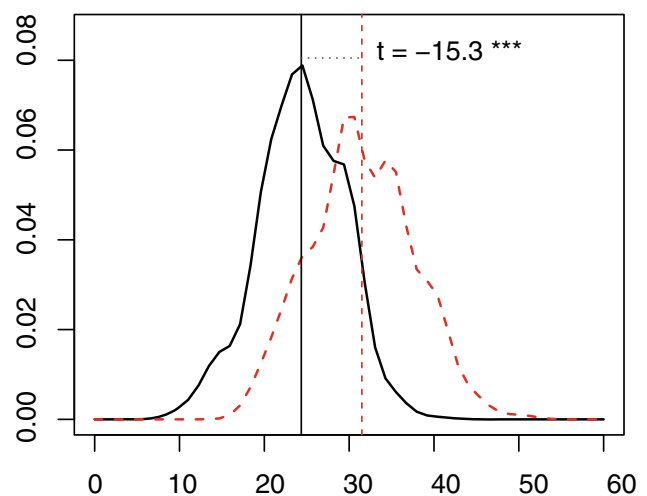

b) Average cooking time for vegetables (minutes)

\section{— Intervention -...- Control}


Fig. 3 Kernel density distribution showing the difference in women's decisions over the home garden (Panel a) and women's empowerment index (Panel b) between control and intervention groups three years after the intervention.

Note: The solid and dotted vertical lines show the means for the intervention and control group, respectively. The t- and $p$-values are derived from the Welch two sample t-test

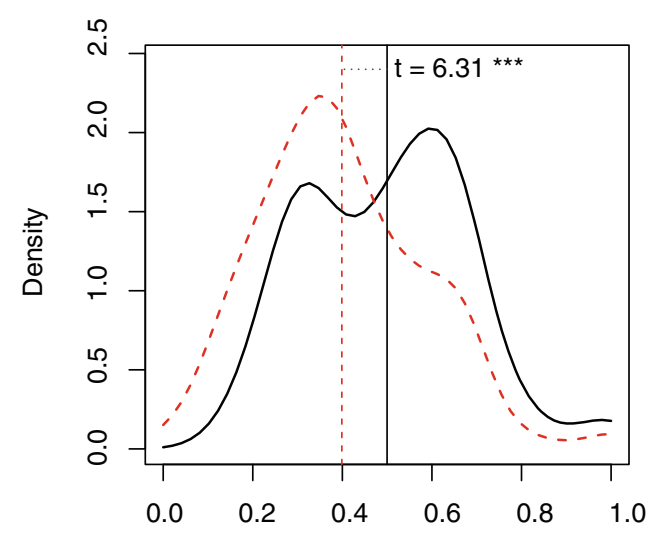

a) Women's decision over the home garden Intervention

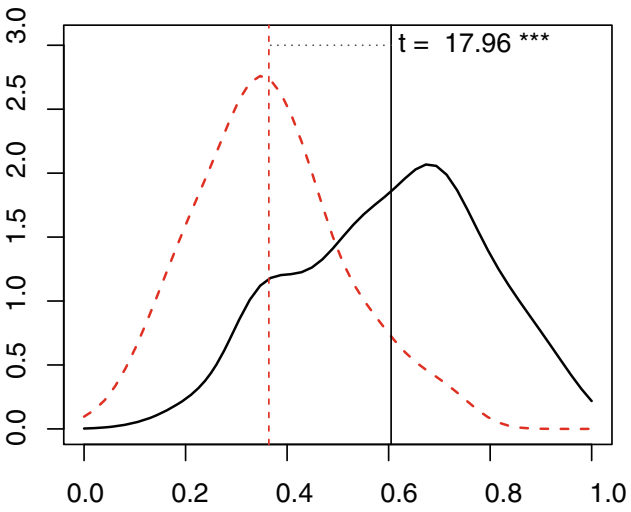

b) Women's empowerment index Control suggests a $28 \%$ improvement in the mean score $(p<0.01)$. Panel (b) shows that women in the intervention group have a self-perceived level of empowerment that was 30\% higher than women in the control group $(p<0.01)$.

\section{Determinants of vegetable production}

The quantity of vegetables produced was regressed on a set of covariates to explain the variation in the data. The explained variance is relatively low (20\% for leafy and $16 \%$ for non-leafy vegetables), yet some covariates are significant (Table 6). Under all specifications, and for both leafy and non-leafy crops, the use of good gardening practices was a strong determinant of sustained vegetable production. Knowledge on the other hand affects total production positively, however this positive effect is mainly associated with non-leafy vegetables. These effects are evident in both the sub-sample of interventiononly households and the full sample (after controlling for being in an intervention households). The dummy variable signifying that a household received intervention is very weakly significant at the $10 \%$, and the coefficient is not significant when analysing the determinants of leafy and non-leafy vegetables separately. These findings show that being part of the intervention group does not have any more an effect on production after controlling for the number of the implemented gardening practices used in the homestead garden and the nutrition knowledge score (which are both strongly significant).This reiterates that the main pathways of the intervention's impact are captured mainly through these two components.

In addition to knowledge and practices, women who experienced challenges in managing the home garden produced less leafy vegetables. Moreover, increased production of non-leafy vegetables was positively associated with being part of a women's group and higher age.

\section{Discussion}

"Good nutrition is the lifeblood of sustainable development" (FAO et al. 2018, p. 13) as good nutrition not only contributes to the achievement of zero hunger (SDG2), but also to several of the other sustainable development goals such as healthy lives (SDG3) and ending poverty (SDG1). It is well-understood that the role of agriculture is fundamental to good nutrition, but there is a lack of evidence for effective pathways showing how agricultural interventions lead to positive nutritional outcomes.

In a recent review of agricultural interventions contributing to nutrition outcomes in South Asia, Bird et al. (2019) identified six intervention studies published from 2012 to 2017 and observed that four of these tested the impact of home gardens. They showed that home garden interventions had a positive effect on intermediate nutritional outcomes such as an improvement in diets, at least during the lifetime of the intervention. A key knowledge gap is whether these effects are also sustained after an intervention ends.

This question is particularly important with regard to the cost-effectiveness of home garden interventions as compared to other nutrition interventions such as fortification and biofortification. Another factor influencing cost-effectiveness, is the potential diffusion of improved gardening methods from trained to non-trained women, which is an important issue but our study did not deal with it. However, a comparison of home gardens with fortification and biofortification is potentially fraught, because home garden interventions provide more than single micronutrients, as they aim to change food systems and human behaviour in terms of what food is being produced, what is consumed, and how.

This study contributed to this branch of literature by showing that the intermediate nutritional outcomes of home garden interventions are sustained at least three years after 
Table 6 Determinants of home garden vegetable production in 2016

\begin{tabular}{|c|c|c|c|c|c|c|}
\hline & \multicolumn{3}{|c|}{ Intervention only } & \multicolumn{3}{|c|}{ Full sample } \\
\hline & (1) & $(2)$ & (3) & (4) & (5) & (6) \\
\hline Total vegetable & $0.07^{*}$ & & & 0.04 & & \\
\hline Production $2013(\mathrm{~kg})$ & $(0.03)$ & & & $(0.03)$ & & \\
\hline Leafy vegetable & & 0.05 & & & $0.04^{*}$ & \\
\hline Production $2013(\mathrm{~kg})$ & & $(0.03)$ & & & $(0.02)$ & \\
\hline Non-leafy vegetable & & & $0.10^{* * *}$ & & & $0.07^{* * *}$ \\
\hline Production $2013(\mathrm{~kg})$ & & & $(0.04)$ & & & $(0.03)$ \\
\hline Practices used in home garden & $17.11^{* * *}$ & $5.77^{* * *}$ & $10.72^{* * *}$ & $14.43^{* * *}$ & $4.84^{* * *}$ & $9.01^{* * *}$ \\
\hline (number of) & $(2.28)$ & $(0.66)$ & $(2.07)$ & $(1.80)$ & $(0.50)$ & $(1.64)$ \\
\hline Challenges in home garden & -3.93 & $-1.98^{* *}$ & -1.68 & -2.44 & $-2.07^{* * *}$ & -0.29 \\
\hline (number of) & $(3.22)$ & $(0.93)$ & $(2.92)$ & $(1.98)$ & $(0.55)$ & $(1.81)$ \\
\hline \multirow[t]{2}{*}{ Knowledge score } & $5.24^{* *}$ & $-1.86^{* *}$ & $7.61^{* * *}$ & 1.06 & $-1.87^{* * *}$ & $3.35^{* *}$ \\
\hline & $(2.57)$ & $(0.75)$ & $(2.32)$ & $(1.73)$ & $(0.48)$ & $(1.58)$ \\
\hline \multirow[t]{2}{*}{ Household size } & -1.72 & $-2.05^{* *}$ & 0.75 & -2.61 & -0.93 & -1.45 \\
\hline & $(2.90)$ & $(0.84)$ & $(2.63)$ & $(2.07)$ & $(0.57)$ & $(1.88)$ \\
\hline \multirow[t]{2}{*}{ Age } & 0.71 & -0.21 & $0.92^{* *}$ & $0.86^{* *}$ & -0.08 & $0.95^{* * *}$ \\
\hline & $(0.49)$ & $(0.14)$ & $(0.44)$ & $(0.37)$ & $(0.10)$ & $(0.34)$ \\
\hline \multirow[t]{2}{*}{ Part of women's group (Yes=1) } & $38.12^{* * *}$ & 3.01 & $35.13^{* * *}$ & $24.67^{* * *}$ & -0.32 & $24.94^{* * *}$ \\
\hline & $(8.95)$ & $(2.59)$ & $(8.12)$ & $(6.95)$ & $(1.91)$ & $(6.34)$ \\
\hline \multirow[t]{2}{*}{ Intervention household (Yes=1) } & & & & $-19.52^{*}$ & -1.86 & -16.88 \\
\hline & & & & $(11.54)$ & $(3.18)$ & $(10.52)$ \\
\hline \multirow[t]{2}{*}{ Constant } & -52.64 & $29.87^{* *}$ & $-87.59^{* *}$ & 2.00 & $24.63^{* * *}$ & -27.34 \\
\hline & $(41.02)$ & $(11.89)$ & $(37.20)$ & $(27.36)$ & $(7.54)$ & $(24.94)$ \\
\hline $\mathrm{R}^{2}$ & 0.18 & 0.20 & 0.16 & 0.18 & 0.20 & 0.15 \\
\hline Num. obs. & 395 & 395 & 395 & 619 & 619 & 619 \\
\hline
\end{tabular}

Notes: ${ }^{* * *} p<0.01,{ }^{* *} p<0.05,{ }^{*} p<0.1$; Standard errors in parentheses; the dependent variable in columns (1) and (4) is "Total Vegetable Production in 2016"; the dependent variable in columns (2) and (5) is "Leafy Vegetable Production in 2016"; the dependent variable in columns (3) and (6) is "Non-leafy Vegetable Production in 2016". Other non-reported control variables include marital status and years of education

an intervention ends: home garden production of vegetables increased by $49 \%(p<0.01)$, and as most of this increased production is consumed by the household, we found a notable increase in the daily per capita consumption of vegetables by $16 \%(p<0.01)$. Additionally, we find that most of these long-term impacts were driven by changes in knowledge and practices, which are the main two components of an integrated home garden intervention. A follow-up study is ongoing to test whether the effect is also maintained after five years.

We found a change in the composition of vegetables produced from the home garden between the first and second endline as households produced relatively more gourds but fewer leafy vegetables. Some of these dynamics may be due to weather shocks. Households were affected by severe drought during the winter (kharif) season of 2014. The endline data therefore showed no significant impact on vegetable production for the winter season (see last row in Table 3). Yet, in 2016 we observe a significant and positive impact for both winter and summer seasons. Since the winter season is the main period for growing cucurbits and the summer season is the main period for growing leafy vegetables, the observed differences in the crop mix may be largely due to differences in weather condition between the two endlines. However, it could also be that households reverted back to traditional habits of producing the vegetables that they produced before the intervention due to taste or market preferences, but with increased volume due to the improved management practices learned.

Beyond the nutritional outcomes, we found that women who participated had a higher level of self-perceived empowerment $(+30 \%$; $p<0.01)$ and greater control over decisions regarding the home garden $(+28 \% ; p<0.01)$. These results provide relevant insights on the drivers of women empowerment in a rural setting, like Bangladesh. There is ample evidence on how development programming and policies in key economic sectors like micro-finance 
and labour markets provide women with more autonomy and empowerment (Duflo 2012). In the case of Bangladesh, most of the existing studies underscore the importance of such direct economic channels of impact, such as schooling stipend programs (Hahn et al. 2018), microfinance (Pitt et al. 2006) or labour market participation over other non-income generating activities (Anderson and Eswaran 2009). In contrast and additional to these works, our findings suggest that small-scale nutrition interventions that target women, such as home gardening, can have strong implications on the status of women both in terms of perceived empowerment as well as decisionmaking. It suggests that small-scale home-based integrated interventions in other sectors can also be key drivers of social change for vulnerable and marginalized women who do not have access to direct economic income-generating opportunities to begin with. In fact, we posit that these identified social changes may in fact reinforce the intended long-term outcomes of the intervention.

We also found evidence that supporting small home gardens in rural Bangladesh was an entry into smallscale output market participation for many women, often providing a first foray into any form of market engagement. The exact mechanisms for this effect are unclear at present and require further research.

\section{Conclusions}

We demonstrate that integrated home garden interventions can lead to sustained, long-term changes in human behaviour that contribute to the increased production and consumption of vegetables in poor rural households. Integrated home garden interventions can therefore be an effective tool to addresses one of the root causes of malnutrition in low-income countries, thereby contributing to the achievement of several sustainable development goals, particularly zero hunger (SDG2).

These changes are brought about by strengthening good gardening practices used by households as well as providing nutritional training on the benefits of vegetables for human health. Furthermore, such integrated interventions have the potential to create positive impact beyond the production and consumption of vegetables, as we found that women participating in the intervention exhibited higher levels of control both in decision-making over the home garden and in empowerment more generally, as well as higher engagement in vegetable sale and market participation.

Future research could address in more detail which components of an integrated program induce which impact, what exactly is the role of female empowerment in achieving these impacts, and how such interventions could be optimized to have long-lasting societal change.
Acknowledgements Funding for this research was provided by the United States Agency for International Development (USAID) under the project "Improving incomes, nutrition, and health in Bangladesh through potato, sweet potato, and vegetables" and long-term strategic donors to the World Vegetable Center: Republic of China (Taiwan), UK Aid from the UK government, USAID, Australian Centre for International Agricultural Research (ACIAR), Germany, Thailand, Philippines, Korea, and Japan. The usual disclaimer applies. We thank the editors and reviewers of this journal for their comments.

\section{Compliance with Ethical Standards}

Conflict of interests The authors declare that they have no conflict of interest.

Open Access This article is distributed under the terms of the Creative Commons Attribution 4.0 International License (http://creativecommons. $\mathrm{org} /$ licenses/by/4.0/), which permits unrestricted use, distribution, and reproduction in any medium, provided you give appropriate credit to the original author(s) and the source, provide a link to the Creative Commons license, and indicate if changes were made.

\section{References}

Alkire, S., Meinzen-Dick, R., Peterman, A., Quisumbing, A., Seymour, G., Vaz, A. (2013). The women's empowerment in agriculture index. World Development, 52, 71-91.

Anderson, S., \& Eswaran, M. (2009). What determines female autonomy? Evidence from Bangladesh. Journal of Development Economics, 90(2), 179-191.

Beal, T., Massiot, E., Arsenault, J.E., Smith, M.R., Hijmans, R.J. (2017). Global trends in dietary micronutrient supplies and estimated prevalence of inadequate intakes. PLOS One, 12(4), e0175,554.

Bhan, M.K., Sommerfelt, H., Strand, T. (2001). Micronutrient deficiency in children. British Journal of Nutrition, 85(S2), S199-S203.

Bird, F.A., Pradhan, A., Bhavani, R., Dangour, A.D. (2019). Interventions in agriculture for nutrition outcomes: a systematic review focused on South Asia. Food Policy, 82, 39-49.

Bushamuka, V.N., de Pee, S., Talukder, A., Kiess, L., Panagides, D., Taher, A., Bloem, M. (2005). Impact of a homestead gardening program on household food security and empowerment of women in Bangladesh. Food and Nutrition Bulletin, 26(1), 17-25.

Chowdhury, A.M.R., Bhuiya, A., Chowdhury, M.E., Rasheed, S., Hussain, Z., Chen, L.C. (2013). The Bangladesh paradox: exceptional health achievement despite economic poverty. The Lancet, 382(9906), 1734-1745.

DFID (2014). Can agriculture interventions promote nutrition? Agriculture and nutrition evidence paper DFID. London.

Duflo, E. (2012). Women empowerment and economic development. Journal of Economic Literature, 50(4), 1051-79.

FAO, IFAD, UNICEF, WFP, WHO (2018). The State of Food Security and Nutrition in the World 2018. Building climate resilience for food security and nutrition. Rome, FAO.

Gertler, P.J., Martinez, S., Premand, P., Rawlings, L.B., Vermeersch, C.M. (2016). Impact evaluation in practice. The World Bank.

Hahn, Y., Islam, A., Nuzhat, K., Smyth, R., Yang, H.S. (2018). Education, marriage, and fertility: long-term evidence from a female stipend program in Bangladesh. Economic Development and Cultural Change, 66(2), 383-415.

Headey, D., Hoddinott, J., Ali, D., Tesfaye, R., Dereje, M. (2015). The other Asian enigma: explaining the rapid reduction of undernutrition in Bangladesh. World Development, 66, 749-761. 
Hillenbrand, E. (2010). Transforming gender in homestead food production. Gender \& Development, 18(3), 411-425.

Hirvonen, K., \& Headey, D. (2018). Can governments promote homestead gardening at scale? Evidence from Ethiopia. Global Food Security, 19, 40-47.

Iannotti, L., Cunningham, K., Ruel, M., et al. (2009). Diversifying into healthy diets: homestead food production in Bangladesh. In Spielman, D., \& Pandya-Lorch, R. (Eds.) Millions Fed: proven successes in agricultural development (pp. 145-151). Washington: International Food Policy Research Institute.

Jain, M. (2018). Large decrease in child stunting despite limited improvement in children's food intake: evidence from rural Bangladesh. Economic Development and Cultural Change, 66(3), 555-583.

Keatinge, J., Yang, R.Y., Hughes, Jd., Easdown, W., Holmer, R. (2011). The importance of vegetables in ensuring both food and nutritional security in attainment of the millennium development goals. Food Security, 3(4), 491-501.

Malapit, H.J.L., Sraboni, E., Quisumbing, A.R., Ahmed, A.U. (2019). Intrahousehold empowerment gaps in agriculture and children's well-being in Bangladesh. Development Policy Review, 37(2), 176-203.

Olney, D.K., Talukder, A., Iannotti, L.L., Ruel, M.T., Quinn, V. (2009). Assessing impact and impact pathways of a homestead food production program on household and child nutrition in Cambodia. Food and Nutrition Bulletin, 30(4), 355-369.

Olney, D.K., Vicheka, S., Kro, M., Chakriya, C., Kroeun, H., Hoing, L.S., Talukder, A., Quinn, V., Iannotti, L., Becker, E., et al (2013). Using program impact pathways to understand and improve program delivery, utilization, and potential for impact of Helen Keller international's homestead food production program in Cambodia. Food and Nutrition Bulletin, 34(2), 169-184.

Olney, D.K., Pedehombga, A., Ruel, M.T., Dillon, A. (2015). A 2-year integrated agriculture and nutrition and health behavior change communication program targeted to women in Burkina Faso reduces anemia, wasting, and diarrhea in children 3-12.9 months of age at baseline: a cluster-randomized controlled trial. The Journal of Nutrition, 145(6), 1317-1324.

Osei, A., Pandey, P., Nielsen, J., Pries, A., Spiro, D., Davis, D., Quinn, V., Haselow, N. (2017). Combining home garden, poultry, and nutrition education program targeted to families with young children improved anemia among children and anemia and underweight among nonpregnant women in Nepal. Food and Nutrition Bulletin, 38(1), 49-64.

Patalagsa, M.A., Schreinemachers, P., Begum, S., Begum, S. (2015). Sowing seeds of empowerment: effect of women's home garden training in Bangladesh. Agriculture \& Food Security, 4(1), 24.

Pitt, M.M., Khandker, S.R., Cartwright, J. (2006). Empowering women with micro finance: evidence from Bangladesh. Economic Development and Cultural Change, 54(4), 791-831.

Rivera, J.A., Hotz, C., González-Cossío, T., Neufeld, L., GarcíaGuerra, A. (2003). The effect of micronutrient deficiencies on child growth: a review of results from community-based supplementation trials. The Journal of Nutrition, 133(11), 4010S4020S.

Ruel, M.T., Alderman, H., Maternal and Child Nutrition Study Group, et al. (2013). Nutrition-sensitive interventions and programmes: how can they help to accelerate progress in improving maternal and child nutrition? The Lancet, 382(9891), 536-551.

Rybak, C., Mbwana, H.A., Bonatti, M., Sieber, S., Müller, K. (2018). Status and scope of kitchen gardening of green leafy vegetables in rural Tanzania: implications for nutrition interventions. Food Security, 10(6), 1437-1447.

Schaetzel, T., Antal, M., Agnes, G. (2014). Household decisionmaking on homestead food production: perceptions on planting, production, and purchases in Bangladesh. Arlington: USAID Strengthening Partnerships, Results, and Innovations in Nutrition Globally (SPRING) Project.

Schreinemachers, P., Patalagsa, M.A., Islam, M.R., Uddin, M.N., Ahmad, S., Biswas, S.C., Ahmed, M.T., Yang, R.Y., Hanson, P., Begum, S., et al (2015). The effect of women's home gardens on vegetable production and consumption in Bangladesh. Food Security, 7(1), 97-107.

Schreinemachers, P., Patalagsa, M.A., Uddin, N. (2016). Impact and cost-effectiveness of women's training in home gardening and nutrition in Bangladesh. Journal of Development Effectiveness, $8(4), 473-488$.

Schreinemachers, P., Brown, S., Roothaert, R., Sobgui, C., Toure, S. (2018). Research to impact: the World vegetable center's household garden model. Acta Horticulturae, 1205, 305-314. https://doi.org/10.17660/ActaHortic.2018.1205.36.

Sraboni, E., Malapit, H.J., Quisumbing, A.R., Ahmed, A.U. (2014). Women's empowerment in agriculture: what role for food security in Bangladesh? World Development, 61, 11-52.

Tesfamariam, B.Y., Owusu-Sekyere, E., Emmanuel, D., Elizabeth, T.B. (2018). The impact of the homestead food garden programme on food security in South Africa. Food Security, 10(1), 95110.

USDA (2015). Nutrient database for standard reference. Agriculture Research Service, United States Department of Agriculture. Washington, DC. http://ndb.nal.usda.gov/ndb/search/list, accessed on 8 Sept 2015.

Weinberger, K. (2013). Home and community gardens in Southeast Asia: potential and opportunities for contributing to nutritionsensitive food systems. Food Security, 5(6), 847-856.

World Vegetable Center (2014). Vegetable nutrient database, Shanhua, Taiwan: World Vegetable Center (p. 35).

World Vegetable Center. (2016). The World Vegetable Center approach to household gardening for nutrition. Shanhua: World Vegetable Center.

Zimpita, T., Biggs, C., Faber, M. (2015). Gardening practices in a rural village in South Africa 10 years after completion of a home garden project. Food and Nutrition Bulletin, 36(1), 33-42.

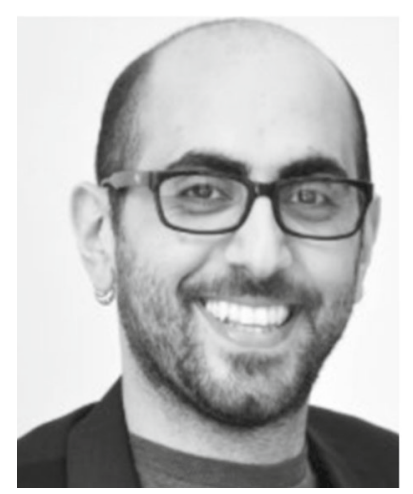

Ghassan Baliki is a research associate at the Economic Development and Food Security Research Group at the Leibniz Institute of Vegetable and Ornamental Crops. He is also a senior researcher at ISDC - International Security and Development Center in Berlin. He holds a $\mathrm{PhD}$ in Agricultural Economics from Humboldt University of Berlin and his expertise is in conducting impact evaluation on food security and resilience in fragile and conflict-affected settings. 


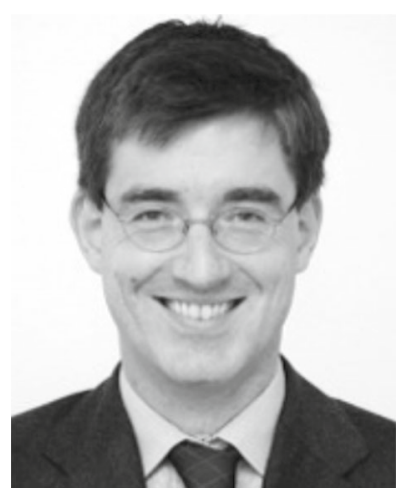

Tilman Brück is the team leader of the Economic Development and Food Security Research Group at the Leibniz Institute of Vegetable and Ornamental Crops. $\mathrm{He}$ is also director of ISDC International Security and Development Center and a Visiting Professor at the London School of Economics and Political Science (LSE). Tilman obtained his doctorate degree in Economics from Oxford University. His research interests focus on the economics of household behavior and well-being in areas affected by violent conflict, and fragility including the impact evaluation of programs in conflict-affected areas.

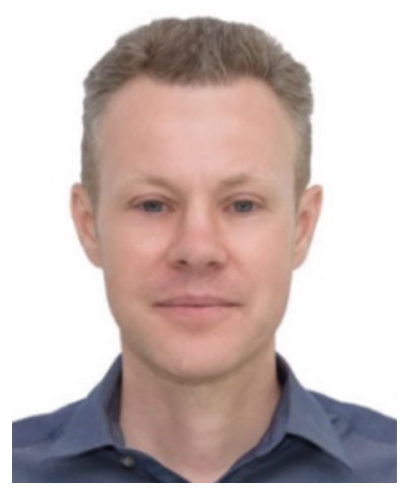

Pepijn Schreinemachers is Lead Scientist - Impact Evaluation at the World Vegetable Center. His expertise is in farming systems research, integrated modeling, and impact evaluation. He holds a $\mathrm{PhD}$ in Agricultural Economics from the University of Bonn, Germany and an MSc in Development Studies from Wageningen University, the Netherlands.

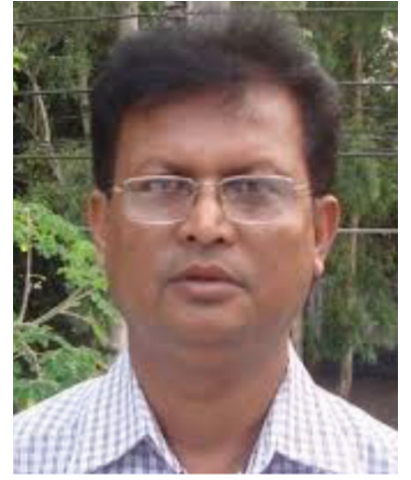

Md. Nasir Uddin is the Executive Director of the Grameen Bikash Foundation (GBF), Bangladesh. He is an expert on Monitoring and Evaluation, focusing on livelihood monitoring, agriculture farming research and integrated pest management (IPM). He also has expertise in participatory monitoring, evaluation and planning (PMEP). $\mathrm{He}$ holds a bachelor?' degree in Agricultural Education (B.Ag.Ed) from the Open University Bangladesh and an MA in Political Science from the National University, Bangladesh. 